\title{
Enduring Values of Ethnic in Managing Multi Cultural Society in Malaysia
}

\author{
Jessica Ong Hai Liaw, Tran Tho Chung, Noor Azmi Mohd Zainol, Wong Wai Loong, \\ S.Inderjit, Nurul Faezah Mohd Talib and Abdul Hamid Moiden \\ National Defence University of Malaysia, Sungai Besi Camp, 57000 Kuala Lumpur
}

\begin{abstract}
Malaysia is a multi-ethnic country which living in harmony and unification. Their cultural, linguistic and religious values are enduring vitality and rich diversity and appeal throughout Malaysia's history. This paper aimed is to demonstrate the enduring values of ethnicity in Malaysia and identified in the building and development of the country. It also addresses the challenges of development and security in the nation-building. Malaysia's efforts in multi-cultural society management, as well as measures to address the challenges of social security and stability will be an important factor in building the sociocultural pillar of ASEAN community in the future. The influence of related ethnic issues in Malaysia such as identifying national culture, national education and national language is still a persistent topic in the national building. The policies of the Malaysian state were formed through the process of 'ethnic bargaining'. This is considered to be an important basis for the reconciliation of various aspirations or the often conflicting demands of ethnic groups. Thus, the difference will be increasing between ethnic groups and it can also be the cause of the struggle to reclaim ethnic interests. The impact of the Malaysian government's policies such as economic, culture, language and education. That is concertized the objectives of the Strategic Plan for Culture of the Association South East Asia Nations (2016-2025) and the implementation of this content is also contributing to the building of ASEAN community which based on three major pillars politicalsecurity community, economic community and sociocultural community.
\end{abstract}

Key words: ethnicity, diversity, reconciliation, socio-cultural community

\section{INTRODUCTION}

Malaysia has more than 200 ethnic groups living in harmony and unification in this country. In any country, the issues of preservation and maintenance national cultural values has always been an important goal in the development of each country and Malaysia is not out of that trend. Therefore, the Government of Malaysia has attended to the implementation of management policies, harmony between the interests of the people, motivation for ethnic groups to participate in building a multi-racial social community, and contribute to the country. However, in a multiracial country like Malaysia there are still some challenges that affect security and social stability. Specifically, differences in language, culture and customs are the issues that are of concern and discussion in conferences.

In general, since independence, Malaysia has been very interested in the issue of ethnicity and has succeeded in managing and maintaining harmony among peoples in a country. This is also one of the important objectives of ASEAN's Cultural and Social Strategy, which is set for the period from 2016 to 2025 . The aim of this paper is to first of all demonstrate that the enduring values of ethnics in Malaysia and this is one of the contents identified in the building and development of the country. Malaysia's efforts in multi-ethnic society management and its harmonious settlement of the challenges related to social security and stability in the country, as well as the avoidance of negative effects from outside. After more than sixty years of building the country, Malaysia has had great success in the management, preservation and development of ethnic cultures. However, besides reconciling the needs of the ethnic groups in society, the Malaysian Government should pay attention to solving problems related to the relationship of ethnic groups and the disagreements to implement process of building the country.

There are three persistent issues that affect the Malaysian national construction process: national language, national culture and national education. To reconcile the different expectations and often conflicting demands of different ethnic groups on these, the Malaysian state formulated policies that emerged through the process of 'ethnic bargaining' [1]. 


\section{ENDURING VALUES OF ETHNIC IN MALAYSIA}

Malaysians are using the electoral process to bargain peacefully. It is clear that the strength of the Malaysian multiracial society is the ability to create to survive a "negotiated existence", dealing with the awkwardness of contradictions towards consensus through a peaceful and a civilized effort conducted at all levels of society [2]. The attractiveness of traditional cultural values is easily stimulated by passion for the purpose of motivating ethnic individuals to preserve, protect and promote their culture, language and religion. Historically, in Malaysia, the affective appeals also became closely intertwined with the instrumental pursuit of political and economic objectives that aimed to manipulate the system and distribution of rewards in preference of the particular ethnic members. Thus, the combination of ethnic groups was more effective and successful than the social classes in mobilizing their members to pursue the common goals of society in Malaysia.

The fact that Malaysia consist of so many races and ethnic group makes it a gastronomical paradise. Different races and ethnic groups have their own way of serving food and their own eating culture. Tourists who come to Malaysia will experience a multiracial and multicultural country first hand. Furthermore, if you were to take a look into Malaysian history, Malaysia has been colonized by many western countries, such as the Portuguese, Dutch, Siam, Japanese and also British. They leave behind not only war traits but also various culture and buildings. However, when it comes to formal dinners, usually traditional Malay food or western food are served. In some occasions where the government tends to promote unity in the country, fusion of food from the three races might be served at the same time.

While much remains to be done to promote interfaith dialogue and understanding, some efforts have been made through the formation and activities of interfaith councils. On the cultural front, the festivals of various ethnic groups are respected, with national or state holidays declared to celebrate them.

In fact, Malaysian people are mainly from three ethnic groups. These are Malay, Chinese and Indian each with a distinctive education and ethnic background and language. This can be the cause of divisions among students who will be based on their mother tongue language. Students will prefer to attend school where their mother tongue language is the language of instruction. For instance, larger part of students would wish to go a school of their ethnic affiliation that is Malay, Chinese and Indian students respectively will join their indigenous schools which exuberates the racial divide and hence leads to a problem that restricted association among the students in various ethnic [3].

The Malay and Non-Malay relations was in a state of uncertainty as neither group was able to determine the other group's intentions as well as the stressed driven by the perceived fear and suspicious of the other group. This situation will allow the emergence of feelings of prejudice, discrimination and distrust, which are prevalent in today's Malay and NonMalay relations. Invariably ethnicity became a wedge in Malay and Non-Malay relations rather than for unity. It influences the Malay and NonMalay to identify loyally with their respective languages, cultures and religions that always created insecurity in ethnic relations and challenged efforts in promoting unity. There is nothing good or positive impacts in due to disharmonic relations between ethnic, only a bad or negative impact. The national leaders are seriously concern on this matter. National security and solidarity among ethnic is the main agenda for country's development. Basically, Malaysian citizens feel the importance of having good relations between ethnic. Only a few or some individuals who do not understand or do not want to understand the importance of having good ethnic relations such as politicians and bloggers will use this issue to get support, influence or just to antagonism the people. In conclusion, solidarity is very crucial factor and must be addressed wisely.

Many government's policies were advanced in an endeavor to create a positive attitude towards cultural assimilation and the making of a national culture. Among them are the National Cultural Policy (NCP) presented in August 1971 under Prime Minister Tun Abdul Razak Hussein to develop a national culture from three elements: the indigenous culture; appropriate components from Non-Malay cultures; and Islam as a vital segment. Beside the national ideology, Malaysia's New Economic Policy (NEP) was first reported as a noteworthy policy response to the race revolts after the election in 1969. The NEP has two aspects, one was poverty alleviation for all races and another social restructuring to eliminate the racial determinant of economic function. The ultimate goal of NEP was national solidarity [2]. The method of reasoning behind NEP depends on the acknowledgment that national solidarity in Malaysia is a prerequisite for developing all parts as of life. In February 1991, the fourth Prime Minister, Tun Dr. Mahathir Mohamad who introduced the new National Development Plan (NDP) replacing the NEP. The NDP of Prime Minister Mahathir Mohamad was considered as the most innovative strategy to promote national solidarity. It likewise was known the "Vision 2020", in which he declared that the making of a "united 
Malaysian nation" or "Bangsa Malaysia" was a prerequisite for aspiring to become a developed industrial nation by 2020. "Vision 2020", he delineated the nation's major challenges in building that was meaning to make a united Malaysian nation, both in territorial level and among ethnic groups based on equality and fairness in society. Vision 2020 features the development of national unity and social cohesion, economic and social equality, political stability and system of government, quality of life, social values and national spirit, pride and confidence. When the worldwide financial crisis struck Malaysia in July 1997, the administration built up the National Economic Action Council, which included agents from the public and private sectors as well as the different ethnic groups.

The negotiations, as a type of regrouping, took place almost immediately. It is clear that Malaysians, particularly those in the Malaysian government, have reliably utilized ethnic bargaining, development planning and the application security proper measures in times of crisis and peace. During period 1981-2003 under the fourth Prime Minister Tun Dr. Mahathir Mohamad, the political sensitivity towards the Non-Malays was decreased remarkably. Among the essential changes were liberalization of language, education policies and the most important is the promotion of nation-building such as "Bangsa Malaysia.

The successive governments in Malaysia has also made considerable efforts to inherit and develop national values. Under Prime Minister Tun Abdullah Ahmad Badawi (2003-1008) attempt to expand on the inward values so the component which was underlined in Islam Hadhari considerations. And recently former Prime Minister Dato' Seri Najib Razak has acquainted One Malaysian slogan to develop a nation. One Malaysia looks to enhance the relationship all Malaysians, regardless of race, religion and culture. The concept, slogan or even the policy of One Malaysia is seen as a continuation from what was presented by past leaders towards social stability and national building. Globalization has additionally given another smoothness to the bounded notion of cultural and national identity. Through the tourism, the portrayal of Malaysia in openly forums and events has predominantly been an exhibiting of Malaysian multi-ethnicity and multicultural. Consequently, at the official level, the dynamic advancement of tourism by both state agencies and the federal government has anticipated the picture of multicultural fluidity between ethnic boundaries. The Tourism's recent fruitful displaying of its multi-ethnic "open-house" festivity draws from various ethnic and religious celebrations, which have been rearranged into a major tourist event. It has been contended that during a time where social orders have progressed toward becoming "globally connected and culturally intertwined" multiculturalism will turn into a more appropriate and significant power. Others have noted how heterogeneity is currently winding up part of the conscious identity of modern societies, reformulating "new hybrid forms" in which "the concepts of sameness and difference are presented as compatible rather than opposed." Thus, "in recent decades, national cultures are often quite openly presented as heterogeneous and fluid communities," no longer requiring the state to project the image of a culturally homogenous entity as proposed by some of the theories of nationalism. In the field of arts, theater, films, and other popular culture, such as music, the globalization process has also seen in Malaysia the beginnings of interactive multi-cultural synergies taking place beyond the "market-place" boundaries that were initially conceptualized in Furnivall's notion of "plural society."

Lately, such inter-ethnic forays have also extended into "new social spaces" engendered by globalization, such as the cyber-cafes that mushroom everywhere throughout the nation. Indeed, "when it comes to globalization and transnational connection youth cultures are in the forefront of theoretical interest: youth, their ideas and commodities move easily across national borders, shaping and being shaped by all kinds of structures and meanings." In Malaysia, the increasing role of this new generation cannot be underestimated in terms of its different positioning and repositioning in civil society, to have the capacity to synergize with and advance some type of "local multiculturalism" in the context of globalization.

The multicultural collaborations in the mainstream culture and arts of the country, the diverse cosmopolitanism, and "hybridization" that have been evolving independently of state cultural policies and intervention will most certainly contribute to the future development of a Malaysian type of multiculturalism. In the field of universal games (through the Commonwealth Games, World Cup Hockey and Youth Soccer competitions, golf rivalries and Formula One dashing), Malaysia has also been advocating for itself as a worldwide host. Be that as it may, sports is likewise an opportunity to extend the image of a multicultural national "team" with the exhortative serenade Malaysia Boleh (Malaysian Can) and donning delegates, for example, a prevalent indigenous sprinter known as the "Flying Dayak".

This worldwide imaging additionally comes to fruition in Malaysia's development of "globalizing images, for example, the twin Petronas Towers, the advanced looking Kuala Lumpur International 
Airport, the modern Light Rail Transit system, Cyberjaya (Malaysia's version of the Silicon Valley), and the Multi-Media Super Corridor, designed as an agglomeration of high-tech enterprises, research and development centers, and a multi-media university. These projects epitomize the Mahathir-led Malaysian nation-state's political will and capacity to synergize with the new knowledgebased economy and the new technologies of globalization. An indirect outcome of all these is the inculcation into its citizens, especially the younger generation, the sense of a new Malaysian consciousness that transcends ethnic identity, and the pride of being a Malaysian who is additionally a star dynamic globalizing member of world society.

\section{NATIONAL-BUILDING}

The term national building is frequently utilized at the same time with state building, democratization, modernization, political improvement, post strife remaking, and peace building, but every idea are different, even though their evolution is intertwined. The concept of national building was known from the end of World War II when American political scientists used into conferences. It was described as the greater integration of state and society, as the responsibility of all citizens brought loyalty to the modern nation state with it. National building can include the utilization of purposeful publicity or significant foundation improvement to cultivate social agreement and economic development. National building is likewise a normative concept that means different things to different people. The most recent conceptualization is basically that national building programs are those in which dysfunctional or precarious or failed states or economies are given assistance in the development of governmental infrastructure, civil society, dispute resolution mechanisms, as well as economic assistance, in order to increase stability. But it is imperative to look at the evolution of theories of nation building and the other concepts which has both been supplanted and included. Many people believe that nation building is evolutionary rather than revolutionary, that takes a long time and a social process that cannot be jump started from outside. The concept of national building often used interchangeably with national integration that contains a vast extent of human relationships and attitudes ranging from the joining of diverse and discrete cultural loyalties, the development or a sense of nationality, the integration of political units into a common territorial framework with a government to exercise power as well as the integration of the citizenry into a common political process to the integration of individuals into an organization for purposive activities: If nation building so touches the root of people's beliefs and attitudes in regard to politics, then the process of nation building must be influenced essentially by the character of a society's political culture.. This will also be the content throughout the process of implementation of specific means such as the creation of a strong economy which will act as the stimulus on which other programs can be built; the stabilization of internal factions and the promotion of domestic tranquility and, the consolidation of cultural competencies including the improvement of the quality of people's lives, and hence the vitality of the nation. After independence in August 1957, the Malaysian state had the first nation building project. It is the Malaysian Constitution which was expected to provide a feasible basis for ethnic understanding and good government. In addition, there was a great important of bargaining of the major issues among ethnic groups and political parties.

These are two core issues to understand the nature and significance of the political process in Malaysia [5]. At this time, these issues are firstly understood as ethnicity is the key and the secondly the Malays would control the country. For the government system to operate, the main ethnic groups would have to work together and political parties are formed on the basis ethnic lines. Vision 2020 is definitely not a run of the mill arrangement yet more than identified with a reaction to the political, economic and social current issues broadly and universally which gave great difficulties to the country. The primary goal of Vision 2020 is to build up Malaysia as a fully developed country by 2020 that covers all fields of life: political, economic, social, spiritual, psychological and cultural. There are challenges identified by the government to accomplish the above destinations. As far as ethnic relations, the challenges in Vision 2020 is to make a general public that practices a developed understanding and tolerant, which the public interest is more important than their own interests. In economic area, the challenges of Vision 2020 are to guarantee the execution of the distribution of national wealth fairly and equitably in which there is full partnership by each citizen in economic development.

\section{MALAYSIA'S ROLE TO BUILD ASEAN COMMUNITY IN THE SOCIO-CULTURE}

Malaysia is one of the five founding members of ASEAN. Malaysian roles are increasingly important. Especially, when ASEAN is implementing the contents towards building an ASEAN community that has been announced in 2003 and officially in effect since 2008, with the three main pillars: political community, economic community and socio-cultural community. Through the implementation of the objectives off the sociocultural community will also promote the 
conservation, preservation and development of cultural heritage of the ASEAN community. The important steps in pursuing a full awareness of the cultural, historical values of the ASEAN Community over the years have made people who has a profound sense of ASEAN identity. In order to further concretize the goals of building a socio-cultural of ASEAN, November 2016, the ASEAN Secretariat issued a Strategic Plan for Culture 2016-2025 which defined key strategies and priority areas of action on the culture. With the success in managing and building a cultural diverse society, Malaysia will make more contributions to the implementation of the ASEAN Strategic Plan for Culture 2016-2025.

\section{The Malaysia's abilities}

\section{i. The Experiences}

During the colonial periods in Southeast Asia, colonial governments used the reduction of cultural complexity within their colonies as a strategy of governance. Indonesia, Thailand, Brunei, Malaysia and Singapore have each developed distinct forms of governing with respect to ethnic diversity. The large number of ethnic groups has been categorized into several standardized ethnic groupings to reduce the complexity to manageable proportions. All these countries experienced ethnic violence in the past, but looking at Malaysia first, the country "...had since been in a state of 'stable tension'...dominated by many contradictions, but Malaysia has managed to solve most of them through a process of consensus seeking negotiations." [2]. Inward migration, both legal and illegal, is still substantial and requires a constant process of integration or assimilation into Malaysian society. Malaysia was predicted to suffer serious bloody ethnic conflicts every time an economic crisis occurred in Asia. However, considering the series of economic crises in the last three decades, namely, the 1986-1987, 1997-1998 and the recent 2009-2012 economic crises, Malaysia remains politically stable and is in fact enjoying positive economic growth. According to Shamsul (2009), "what many have failed to realize is that all the predictions of the prophet of dooms have not come true. Instead, since the major ethnic riot in May 13th 1969, there has been consistent long peaceful period, punctuated once or twice by ethnic skirmishes. Instead, all the riots and conflict have been happening in the north of peninsular Malaysia, in the once famous 'peaceful' Thailand" [2]. While there are lessons to be learned from the Malaysian experience of governing a multiethnic nation, the conditions specific to Malaysia - history, political culture, level of economic development, population make-up itself are not present in those countries. But there is a feature in this practice of the politics of accommodation in Malaysia that has kept the country together: that is the existence of political elites in each ethnic group whose continuity and wellbeing depends on the working of the formula. This essentially means cooperation and consensus among the elites. Thus at the top and at the bottom of the pyramid there is a congruence of purpose to keep the system going. In the Malaysian political culture, it is pragmatism that dominates, resulting in giving preference to what is workable rather than to what is right. It has also been the characteristic of the politics of accommodation in Malaysia, shaped by its pluralism. Blessed with a vastly diverse multiracial population comprising a plethora of divergent political views and religious aspirations, Malaysia's nation-building efforts have been a unique experiment. Since the colonial period, the country had to contend with three large and distinct ethnic groups, which largely, due to history, could be identified most closely by their role and place in Malaysia's society and economy. Upon gaining independence, this nascent polity was confronted with a colossal task to unite the various ethnic groups in the country under a single national vision and a cohesive economic development strategy.

\section{ii. The Guide and Connectivity Capabilities}

ASEAN Charter is one of the ideas suggested by Malaysia which was mentioned in the Vientiane Plan of Action in 2004. In 2005, Malaysia hosted the summit where there was a declaration to appoint an Eminent Persons Group to come out with recommendations on the charter. All other member countries then contributed their part to the Charter as a consensus. In addition, Malaysia initiated the of ASEAN+3 summit, namely ASEAN and China, Japan and South Korea, which was later renamed as the East Asia Economic Caucus (EAEC) by Malaysia's fourth Prime Minister Tun Dr. Mahathir Mohamad. It is responsible for the East Asia Summit (EAS) and created the slogan used as Motto of ASEAN: 'One Vision, One Identity, One Community'.

The fact, Malaysia has contributed quite a few ideas of statecraft already tried in various diplomatic situations, which can be applied in the new ASEAN: Starting early in the 1980s with its diplomacy of neutrality, Malaysia saw the region agreeing to a Declaration for the Neutralization of Southeast Asia in a Zone of Peace, Freedom and Neutrality (ZOPFAN); After ZOPFAN followed the diplomacy of South-South Cooperation in the 1990s that championed win-win cooperation between countries in the south founded on the principles of Smart Partnership and the convening of the Langkawi International Dialogues; In 2010, Malaysia launched at the United Nations a third initiative at statecraft called the diplomacy of moderation aimed at mitigating the use of the forces of violence as a means of settling disputes between countries and among interest groups. It must be noted that 
resorting to moderation must not be construed as a sign of weakness.

The ASEAN is composed of 10 nations which are Brunei, Cambodia, Indonesia, Laos, Malaysia, Myanmar, the Philippines, Singapore, Thailand and Vietnam. The year 2015 was very important for ASEAN because that was when they realized the ASEAN Community. As for Malaysia, 2015 is a crucial year as it is the chair of ASEAN. The creation of an ASEAN Economic Community (AEC) on 31 December 2015 was one of the goals which would integrate the region's 600 million people and economies with a combined GDP of $\$ 2.5$ trillion. Malaysia plays an important role in managing such high expectations by guiding 10 ASEAN countries to regional integration in advancing regional stability, building prosperity, and addressing global challenges. The formulation of the "post-2015" 10 year roadmap for this community-building exercise had been launched by Malaysia.

In National Colloquium on Malaysia's Chairmanship of ASEAN 2015, Former Prime Minister Dato' Seri Najib Razak emphasized the creation of a "People-Centered ASEAN" and would no longer be only the domain of elite and specialists. This is because ASEAN has been criticized as an elite-driven and state-centric project: the activities and projects of ASEAN are only known among experts, political leaders, and government officials, but little information distributed to the citizens and concerned stakeholders. Hence, the primary goal of Malaysia is to establish of a "people-centered ASEAN" by creating a greater sense of belonging among the people of ASEAN. This is reflected in the overall - "Our People, Our Community, Our Vision."

Malaysia has been successful in turning a new chapter in regional integration in 2015, the year it served as the Chair of the Association of Southeast Asian Nations (ASEAN). The priorities include officially establishing the ASEAN Community by the year's end, developing ASEAN's post-2015 vision, strengthening ASEAN's institutions, steering ASEAN closer to its people, fostering the development of small- and medium-sized enterprises (SMEs), expanding intra-ASEAN trade and investment, promoting regional peace and security and enhancing ASEAN's role as a global player.

According to Former ASEAN Secretary-General Le Luong Minh, Malaysia, as one of the founders of ASEAN, has an experienced team of officials and strong commitments from state leaders to the formation of ASEAN Community. ASEAN has fulfilled about 97 percent of all tasks in the Roadmap for an ASEAN Community to date, in which 100 percent of priority measures for the establishment of the Political-Security and Socio-Cultural Communities have been done while 93 percent of tasks for the ASEAN Economic Community have been completed. Under Malaysia's chair, the bloc has made significant progress towards enhancing public-private partnership in projects within the framework of Master Plan on ASEAN Connectivity. In addition, the 2015 chair has carried out various initiatives to ramp up people-to-people exchange, notably between NGOs, law-makers, businesses and young entrepreneurs, in the region. In order to escort the ASEAN toward achieving a people-centered ASEAN, not only Malaysia, but other member states must stay on course and maintain unity despite diversity. Though accomplishing these deliverables will be challenging, ASEAN must endeavor to complete them as they are important for all countries in ASEAN.

Other priorities that we are working on include strengthening the development of SMEs in the region, expanding intra-ASEAN trade and investment, and enhancing ASEAN's role as a global player. As chair, Malaysia also plans to advance the following initiatives in 2015: an ASEAN trade facilitation agreement, the ASEAN Business Travel Card, the 10th Package of Services Liberalization under the ASEAN Framework Agreement on Services, the self-certification scheme under the ASEAN Trade in Goods Agreement, the Post-2015 Strategic Action Plan for SME Development (2016-25), and the ASEAN Single Window. Another important objective is to deliver the plan for the ASEAN Community 2025, which includes the ASEAN Community Vision 2025, the Kuala Lumpur Declaration on the ASEAN Community Vision 2025, and three attendant documents constituting the political-security, economic, and socio-cultural work plans. Malaysia is chairing the High-Level Task Force for the ASEAN Economic Integration Working Group on Post-2015 Economic Vision and hopes to launch the ASEAN Community 2025 plan in November 2015. Economic measures taken beyond 2015 will be premised on sustaining and promoting ASEAN's economic growth and competitiveness by further removing barriers to trade and investment and by adopting an even more ambitious economic integration program.

These efforts aim to address structural and regulatory barriers in the region through domestic regulatory and legal reforms; institute greater tradefacilitative measure to further strengthen and broaden ASEAN as an integrated production and supply chain; promote new and improve existing infrastructure facilities to create a highly integrated and connected region to meet the challenges of the rapidly changing global economic environment; 
enhance financial services liberalization, including the integration of capital markets; promote the adoption of new technologies to ensure sustainable development; and improve human resource development, including by enhancing mobility among skilled workers in the region to attract talent to meet the requirements of industries. Our post2015 work will require full cooperation and commitment from all member states and is not the sole responsibility of the chair. According to a wellknown proverb, "if you want to walk fast, walk alone. If you want to go far, walk together." As a grouping that has existed for 47 years, ASEAN represents the latter.

\section{iii. The Modern Education System}

Malaysia has developed a fairly advanced and modern educational system, especially at the tertiary level, that has been responsible for raising the educational and skill levels of the society, and has contributed significantly to this transformation. The emergence of a multiethnic and educated middle class, particularly the new Malay middle class with changed mind-sets, values, and orientations reflecting a new sense of confidence has enabled the various ethnic groups to live and work together in relative peace. The NEP introduced the quota system in student admission in order to ensure a balanced ethnic composition, not only in the total population of students but also in the distributions of students according to faculties. Besides, scholarships, special assistance and tuition as well as pre-medical, prescience and pre-engineering programmers were established for rural students. The administration likewise opened the MARA Institute of Technology (ITM) in 1967 to provide food for the advanced education needs of the Malays and Bumiputera. In balance of subject talked dialect as an imperative animal towards ethnic coordination and advancement of national personality, the college in the rustic territory were coordinated to utilize the Malay dialect as the medium of direction for all courses by 1983 [4]. In the period of globalization, the workplace of higher rearing is firmly connected to the outgrowth of a spot mechanical economy, in which productiveness depends dominatingly on science, innovation, and administration. Along these lines, college everywhere throughout the mankind began their rebuilding praxis with a specific end goal to react to this new advancement. In Malaya, this initially came as corporatization of state funded college. The purpose was to create corporate culture and example that empowered colleges to contend in the commercial center [6] declares that, "... as opposed to creating and transmittal noses as social great, the colleges are setting accentuation on the result of learning as an attractive decent and saleable item. Colleges are locked in with advertise related exercises". In the nation, Lee expressed that these progressions have likewise extended the part of the legislature from being the fundamental supplier to a representative and defender of advanced education. This is in short letter with the foundation of The Ministry of Higher Pedagogy in 2004. Advanced education in Malaysia is no thirstier intended to satisfy the requirements of Malaysians as it were. In this period of globalization, training is fasting turning into an industry, and learning is viewed as an item. Limited time material and battles were done in outside country zone to draw in understudies to enlist in neighborhood colleges. This has brought about an expanding routine of remote understudies, particularly from creating nations in Asia and Africa. All these new developments will surely realize another type of multicultural experience to the different ethnicities in Malaysia.

\section{CONCLUSION AND RECOMMENDATIONS}

The success of 'Ethnic bargaining' has resolved specific issues regarding the rights and responsibilities of the citizens as well as practicing the sharing of political power between ethnic parties in Malaysia. This not only maintain the stability of social politics, creating favorable conditions for the development of the country's economy but also helps preservation, retention and development of cultural values of ethnic groups. This is an amazing success in the management and administration of social in Malaysia.

As a plural society, nation-building has always been the greatest challenge for Malaysia. Nation building basically refers to a process of constructing national identity that could accommodate ethnic pluralism while simultaneously inculcating an overarching sense of nationhood. It is usually a process associated with plural societies [7]. The values of the multi-ethnic and multicultural nation have been contributing to the nation building, creating a multicolor image only in Malaysia as the slogan of the Malaysian tourism industry "Truly Asia". However, the plural society in Malaysia will not be able to avoid conflicts of interest among ethnic groups. That is always poses challenges for the government in the process of nation building, because the endurable nature of the ethnic bargaining, it can be affected and melted, especially when the issue of ethnic and religious are politicized. In the context of globalization and booming information today requires the government who has too often resolve the harmonious ethnic relations. It also contributes to the ASEAN socio-cultural community building process. In the national building process, besides solving economic issues, the government also concerns and solves security challenges. These issues are urgent and essential in the trend of integration in globalization. By the instability in the country will be a talking point at the global level. 
The image of the country in the world will be affected and will become worse when we will be denied to collaborate or making relationship with other countries.

The country will be withdrawn due to this instability and without peace and stability; it is difficult for the country to do something that can attract the other countries or collaboration or making investment. On the other hand, if there is unity and harmonious relationship among people or ethnic, the country image will be good. The country will be respected by the others and also be a model or reference. Good collaboration or relationship with other countries will successfully be held and it will be many opportunities or cooperation and bring the benefit to political, economic and social. This will improve the tourism industry when the number of tourist increase and improve the economic development as the investors will invest to their country.

The nature of multi-ethnic culture, some states contemplate the need for the extension of national identity with the goal to ensure country's identity and not the ethnic group identity. It is likewise a method for de-emphasizing ethnicity, in spite of the fact that this point, it has not achieved its intended objective of achieving national unity as Malaysia's society is increasingly becoming politicized and partitioned especially during 1980s [8].

The ethnic groups who want to maintain and use their mother tongue, do not want to learn other language, so will exist a few distinct educational models at their school. This will negatively impact to the building a united nation. Further, students who are studying at the school will become the leaders of the country in the future. If they lack of understanding of the culture, language, and customs of other ethnic, it will lead to the risk of disunity among ethnic groups and social instability. The ethnic groups will always protect their own cultural and linguistic identity for their future generations. This will be able form the negative mentality in the relationship of youth such as choosing friends, workplace, job and so on. Even they can have difficulty communicating with other ethnics in their country. Ethnic relations and ethnic unity are very important issues in a multi-ethnic society in Malaysia. Every Malaysian citizen need to understand a harmonious ethnic relationship would be the key to social stability and development of the country. Therefore, educational and propagandist's duties play an important role in helping people understanding about the enduring ethnic values to the nation's existence.

\section{REFERENCES}

[1] Ruhanas, H. (2010). The Politics of Accommodation and the Problem of Nationbuilding in a Plural Society: The Case of Malaysia. Islam and Civilizational Renewal (Vol. 1, Issue 4) Publisher: Pluto Journals.

[2] Shamsul Amri, B. (2009). Multi-ethnic Keeping The Balance Pays Off, published in The Star, March 26, 2009.

[3] Khairul Anuar, Jessica, O.H.L. \& Ahmad Azan, R. (2015) Malaysia: Ethnic Issues and National Security. Vol. 5, No. 9(1); September. 136.

[4] Rozita, I., Nazri, M. \& Ahmad Hidayat, B. (2011). Multiculturalism and Higher education in Malaysia. Procedia - Social and Behavioral Sciences, 15 (1003-1009.

[5] Suhana S \& Ray Ikechukwu Jacob (2012). Managing Ethnic Conflict for Nation Building: A Comparative Study between Malaysia and Nigeria. Asian Social Science. DOI:10.5539/ass. v8n7p69, Vol. 8, No. 7; June.

[6] Lee Hock Guan (2000). Ethnic Relations in Peninsular Malaysia: The Cultural and Economic Dimensions. Social and Cultural Issues No. 1.

[7] Mohamed Mustafa, I (2002). Managing Ethnicity and Constructing the 'Bangsa Malaysia' (A United Malaysian Nation, Universiti Utara Malaysia. Malaysian Management Journal 6 (1 \&2) 99-1 15.

[8] S.K.Gill, Language Policy Challenges in MultiEthnic Malaysia (2014). Multilingual Education 8, DOI 10.1007/978-94-007-7966-2_2, Springer Science+Business Media Dordrecht. 